\title{
Breeding of spring bread wheat for resistance to fungal pathogens in Western Siberia
}

\author{
Belan I.A. ${ }^{1}$, Rosseeva L.P. ${ }^{1}$, Blokhina N.P. ${ }^{1}$, Lozhnikova L.F. ${ }^{1}$, Nemchenko V.V. ${ }^{2}$, \\ Abakumov S.N. ${ }^{3}$, Cadikov R.K. ${ }^{4}$, Trubacheeva N.V. ${ }^{5}$, Pershina L.A. ${ }^{5}$ \\ ${ }^{1}$ Omsk Agrarian Scientific Center, Omsk, Russia \\ ${ }^{2}$ Agrocomplex "Kurgansemena", Kurgan, Russia \\ ${ }^{3}$ FSUE "Ishimskoe", Tobolovo, Tumen region, Russia \\ ${ }^{4}$ Agrotechstroy, Ufa, Bashkortostan, Russia \\ ${ }^{5}$ Institute of Cytology and Genetics, SB RAS, Novosibirsk, Russia \\ *belan_skg@mail.ru
}

In connection with the mass spread of fungal pathogens, the task of breeders to produce highly productive and stress-resistant varieties. In our works, introgression lines of wheat, carriers of the genetic material of its relatives - T. durum, T. dicoccum, T. dicoccoides, Agr. elongatum, Agr. intermedium, T. timopheevii, S. cereale, are involved in hybridization to obtain initial material for breeding. Due to the inclusion of alien genetic material, the varieties that inhibit the development of leaf pathogens were produced: Omskaya 37, Omskaya 38, Omskaya 41, Sigma 2, Pamyaty Maystrenko, Uralosibirskaya. One of the direction of our work is the utilization of alloplasmic genotypes (H. vulgare)-T. aestivum and $\mathrm{DH}$ lines with a fixed combination of resistance genes of different origin. So, hybrid form 311/00-22 developed from the crossing of the alloplasmic DH(1)-17 line with line Com37 (CIMMYT), the source of the translocation $1 R S .1 B L$, proved to be successful for breeding. Lines L-311(1)-L-311(6) showed their advantage in comparison with the standard varieties for resistance to leaf and stem rust, yield, and grain quality. The breeding tests of alloplasmic lines L-311(5), L-311(4), L-311(6) resulted in varieties of spring bread wheat Sigma, Uralosibirskaya 2 and Ishimskaya 11, respectively. Line L-311(3) entered the pedigree of the new variety Karavai. These results confirm the fact that gene $\mathrm{Sr} 31$ remains effective for protection against stem rust in the Omsk, Kurgan, Tyumen regions and Bashkortostan. DH lines that combine genes for resistance to powdery mildew, leaf and stem rust are studied. New lines are estimated for resistance to $U g 99$ and yellow rust in Kenya (KARI).

Acknowledgements: Some aspects of this work were supported by project No. 0324-20190039 and the RFBR grant No. 17-04-01738. The authors are grateful to A.I. Morgunov and S.N. Sibikeev for the provided introgression lines. 